\title{
SISTEM INFORMASI AKADEMIK DI SMP NEGERI 5 KUPANG BERBASIS WEB
}

\author{
Petrisia W Sudarmadji ${ }^{1}$, Nicodemus M. S², Damiano Stefano Luya Mehang ${ }^{3}$
}

\begin{abstract}
Abstrak :
Pengusulan Program Penelitian dan ini merupakan pelengkap penjelasan secara teknis bagi peneliti dan pelaksana dalam pemanfaatan Teknologi Informasi agar system dapat dimanfaatkan seefektif mungkin pada SMP Negeri 5 Kupang untuk mendukung kegiatan operasional seharihari, baik dalam proses pencarian data siswa, guru, absensi, maupun penilaian, dan proses backup data agar tidak membutuhkan waktu yang cukup lama untuk melakukan kegiatan-kegiatan tersebut. Selain itu, sistem yang sedang berjalan pada SMP Negeri 5 Kupang ini menggunakan media kertas yang kurang menunjang untuk jangka waktu yang panjang karena jumlah data guru dan siswa yang banyak,maka data yang ditampungakan semakin besar, sehingga akan memperlambat kinerja sistem untuk menyajikan informasi secara cepat dan tepat. Metode yang di gunakan dalam penelitian ini adalah : metode observasi, studi pustaka dan perancangan sistem. Tujuan penelitian ini adalah : dengan menggunakan sistem dan perancangan aplikasi yang terkomputerisasi, maka semua data dapat tersimpan dengan rapi, keamanan terjamin, pengolahan data atau informasi dapat dilakukan secara cepat, tepat dan akurat.
\end{abstract}

Kata Kunci : Sistem informasi, Akademik, Pemrograman.

\section{PENDAHULUAN}

Teknologi di bidang komputer saat ini sangat berkembang pesat sehingga dapat meningkatkan keefisienan dan efektifitas dalammelakukan setiap pekerjaan. Komputer bukanhanya sekadar pengolah data dan gambar saja tetapi penggunaannya semakin meluas dan menjadi salah satu sarana komunikasi, media informasi dan edukasi. Saat ini adalah jamannya internet dimana batasan waktu dan jarak tidak berarti lagi bagi media yang satu ini. Kita dapat berkomunikasi dengan siapa saja dan dimana saja di seluruh dunia ini dengan menggunakan fasilitas e-mail maupun dengan cara chatting. Mungkin pada saat ini hampir setiap orang sudah memiliki $e$-mail untuk dapat bergabung di internet.

Oleh karena itu, Dengan pemanfaatan dan penerapan teknologi informasi, kumpulan data yang saling berhubungan satu sama lain dapat diorganisasikan menjadi sebuah file, dimana data-data diorganisasikan kemudian disimpan kedalam komputer untuk memudahkan pemakai dalam mengakses data.

Dengan menggunakan sistem dan perancangan aplikasi yang terkomputerisasi, maka semua data dapat tersimpan dengan rapi, keamanan terjamin, pengolahan data atau informasi dapat dilakukan secara cepat, tepat dan akurat dibandingkan cara yang belum menggunakan sistem dan aplikasi yang belum terkomputerisasi.

Namun pemanfaatan Teknologi Informasi belum dimanfaatkan seefektif mungkinpada SMP Negeri 5 Kupang untuk mendukung kegiatan operasional sehari-hari, baik dalam proses pencarian data siswa, guru, absensi, maupun penilaian, dan proses backup data

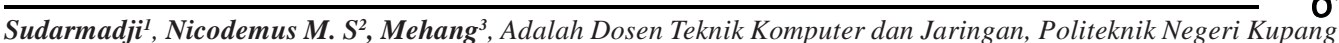


sehingga membutuhkan waktu yang cukup lama untuk melakukan kegiatan-kegiatan tersebut. Selain itu, sistem yang sedang berjalan pada SMP Negeri 5 Kupang ini menggunakan media kertas yang kurang menunjang untuk jangka waktu yang panjang karena jumlah data guru dan siswa yang banyak maka data yang ditampung akan semakin besar, sehingga akan memperlambat kinerja sistem untuk menyajikan informasi secara cepat dan tepat. Masalah lain yang timbul adalah pencarian data berdasarkan kelas dan tahun ajaran yang apabila dilakukan secara tertulis akan memakan waktu yang cukup lama.

Oleh karena itu, memberikan ide buat penulis untuk membuat suatu sistem berbasis web yang bisa memberikan kemudahan bagi para guru di SMP Negeri 5 Kupang, maka atas dasar pertimbangan itu, penulis tertarik membuat suatu website pendidikan (sekolah) dengan judul :

\section{AKADEMIK PADA SMP NEGERI 5}

\section{TINJAUAN PUSTAKA}

Sistem adalah kumpulan dari komponen atau elemen yang berinteraksi untuk mencapai tujuan tertentu. Pengertian sistem dapat dikelompokkan dalam dua kelompok dalam mendenifisikan sistem yaitu penekanan pada prosedurnya dan menekankan pada komponen atau elemennya. Denifisi sistem itu sendiri yang menekankan pada komponen atau elemen memiliki pengertian yang lebih luas dari pada penekanan pada prosedur karena pengertian tersebut lebih diterima dikarenakan suatu sistem terdiri dari beberapa subsistem-subsistem (Jogiyanto, 2005 : 2). Jadi dapat disimpulkan bahwa sistem dapat didefinisikan sebagai suatu kesatuan yang terdiri dari dua atau lebih komponen elemen atau subsistem yang berinteraksi untuk mencapai suatu tujuan.

\section{METODE PENELITIAN}

\section{a.Metode Obervasi}

Mengadakan penelitian secara langsung terhadap objek yang akan diteliti oleh penulis.

\section{b.Metode Studi Pustaka}

Mengambil artikel-artikel dari internet, mengambil referensi dari buku-buku yang berhubungan dengan materi.

\section{c. Model Perancangan Sistem}

Metode yang digunakan dalam pembuatan Sistem Informasi Akademik DI SMP Negeri 5 Kupang bebasis web adalah:

\section{Menentukan Diagram Konteks}

Berikut adalah gambaran sistem informasi Akademik di SMP Negeri 5 Kupang berbasis web adalah :

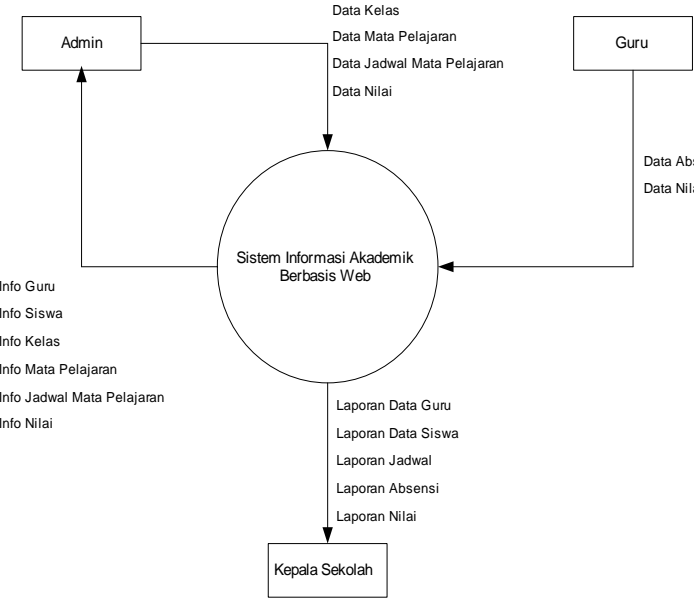

Gambar 1. Diagram Konteks

Berikut adalah penjelasan dari gambar diagram konteks perancangan sistem

- Admin menginput data Guru, Siswa, Kelas, Mata Pelajaran, Jadwal Mata Pelajaran dan Nilai.

- User Guru menginput data absensi siswa dan nilai siswa.

- Kepala sekolah memperoleh output berupa laporan dari data yang di input.

\section{Desain Alur Sistem dengan DFD ( Data} Flow Diagram)

Untuk memudahkan kita mengetahui gambaran proses kerja dari sistem yang akan dibangun, maka perlu dibuatkan bagan alur sistem. Berikut adalah gambaran alur sistem 
informasi akadmik di SMP Negeri 5 Kupang menggunakan system DFD ( Data Flow Diagram).

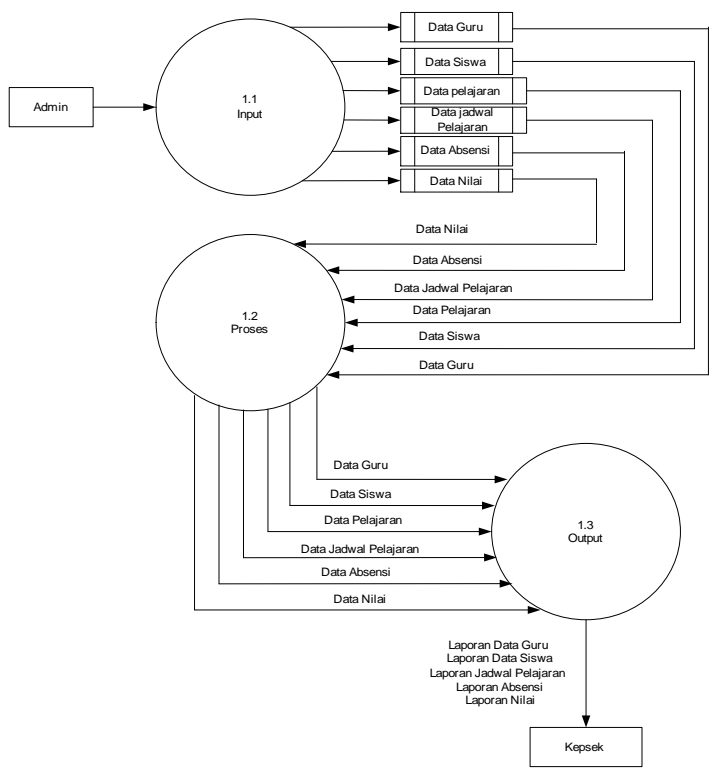

Gambar 2. DFD ( Data Flow Diagram).

\section{Desain ERD (Entity Relationship Diagram)}

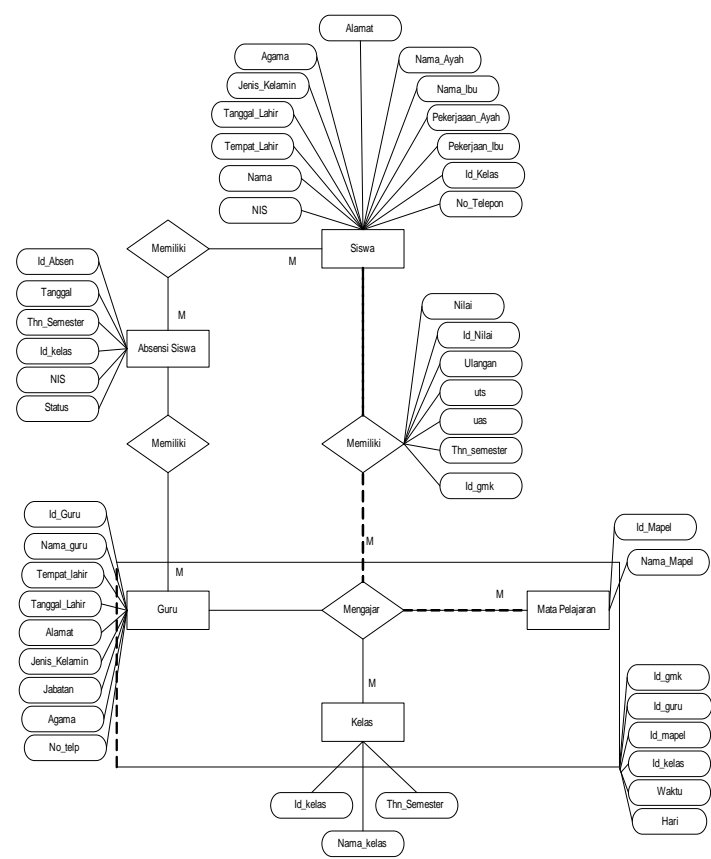

Gambar 3. Desain ERD

\section{HASIL DAN PEMBAHASAN}

\subsection{Hasil Pembuatan Sistem}

\section{a. Halaman Login}

Halaman login merupakan halaman yang akan ditemui pertama kali saat membuka web ini. Pengguna wajib memasukan username dan password untuk dapat masuk pada halaman admin, guru dan pimpinan. Tampilan Login dapat dilihat pada gambar 4 .

Gambar 4. Tampilan Halaman Login

\section{b.Halaman Admin}

Halaman admin akan ditemui oleh pengguna jika pengguna memasukan akun dengan level admin saat melakukan proses login.

- Halaman Home

Pada halaman ini, terdapat link untuk mengakses halaman data user, data guru, data siswa, data kelas, mata pelajaran, jadwal mata pelajaran, nilai, dan laporan. Berikut ini tampilan halaman home dapat dilihat pada gambar 5 .

Gambar 5. Tampilan Halaman Home

- Halaman Data Guru

Pada halaman data guru, akan menampilkan data guru yang telah dimasukan sebelum- 
nya. Berikut ini tampilan halaman data guru, dapat dilihat pada gambar 6 .

Gambar 6. Tampilan Halaman Data Guru

- Halaman Tambah Data Guru

Pada halaman tambah guru, admin dapat menambah data guru dengan cara mengisi form yang telah disediakan. Berikut ini tampilan halaman tambah data guru dapat dilihat pada gambar 7 .

Gambar 7. Tampilan Halaman Tambah Data Guru

- Halaman Edit Data Guru

Halaman ini akan ditemui admin saat admin ingin mengedit data guru. Berikut adalah pengkodean untuk halaman edit data guru.

Gambar 8. Tampilan Halaman Edit Data Guru
- Data Siswa

Pada halaman data siswa, akan menampilkan data siswa yang telah dimasukan sebelumnya. Berdasarkan ini tampilan hala-man data siswa dapat dilihat pada gambar 9 .

Gambar 9. Tampilan Halaman Data Siswa

- Halaman Tambah Data Siswa

Pada halaman tambah siswa, admin dapat menambah data siswa dengan cara mengisi form yang telah disediakan. Berikut adalah tampilan halaman tambah data siswa dapat dilihat pada gambar 10 .

Gambar 10. Tampilan Halaman Tambah Data Siswa

- Halaman Edit Data Siswa

Halaman ini akan ditemui admin saat admin ingin mengedit data siswa. Berikut adalah tampilan halaman ubah data siswa dapat dilihat pada gambar 11 .

Gambar 11. Tampilan Halaman Edit Data Siswa 
- Halaman Data Kelas

Pada halaman data kelas, akan menampilkan data kelas yang telah dimasukan sebelumnya. Berikut adalah tampilan halaman data kelas dapat dilihat pada gambar 12 .

Gambar 12. Tampilan Halaman Data Kelas

\section{- Halaman Tambah Data Kelas}

Pada halaman tambah kelas, admin dapat menambah data kelas dengan cara mengisi form yang telah disediakan. Berikut adalah tampilan halaman tambah data mata pelajaran dapat dilihat pada gambar 13 .

Gambar 13. Tampilan Halaman Tambah Data Kelas

- Halaman Jadwal Mata Pelajaran Pada halaman jadwal mata pelajaran, akan menampilkan data mata pelajaran yang telah dimasukan sebelumnya. Berikut adalah tampilan halaman jadwal mata pelajaran dapat dilihat pada gambar 14 .
Gambar 14. Tampilan Halaman Jadwal Mata Pelajaran

- Halaman Tambah Jadwal Mata Pelajaran Pada halaman tambah jadwal mata pelajaran, admin dapat menambah data jadwal mata pelajaran dengan cara mengisi form yang telah disediakan. Berikut adalah tampilan halaman tambah jadwal mata pelajaran dapat dilihat pada gambar 15 .

Gambar 15. Tampilan Halaman Jadwal Mata Pelajaran

c. Halaman Guru

Halaman guru akan muncul jika pengguna memasukan akun dengan level guru saat melakukan proses login.

- Halaman Home

Pada halaman ini, terdapat link untuk mengakses halaman absensi siswa dan data nilai siswa. Berikut adalah tampilan halaman home guru dapat dilihat pada gambar 16.

Gambar 16. Tampilan Halaman Home Guru 


\section{Jurnal Ilmiah FLASH Volume 3 Nomor 2 Desember 2017}

- Halaman Absensi Siswa

Halaman absensi berisi data-data siswa dari masing-masing kelas yang akan diabsen oleh guru. Berikut adalah pengkodean untuk halaman absensi. Berikut ini tampilan halaman absensi siswa dapat dilihat pada gambar 17.

Gambar 17. Tampilan Halaman Absensi Siswa

\section{- Halaman Nilai Siswa}

Pada halaman nilai siswa, akan menampilkan data nilai siswa dari masingmasing kelas yang telah dimasukan sebelumnya. Berikut adalah tampilan halaman nilai siswa dapat dilihat pada gambar 18 .

Gambar 18. Tampilan Halaman Nilai Siswa

- Halaman Tambah Nilai Siswa

Pada halaman tambah nilai siswa, guru dapat menambah data nilai siswa dengan cara mengisi form yang telah disediakan. Berikut adalah tampilan halaman tambah jadwal nilai siswa dapat dilihat pada gambar 19.
Gambar 19. Tampilan Halaman Tambah Nilai Siswa

\section{d.Halaman Kepala Sekolah}

Halaman kepala sekolah akan muncul jika pengguna memasukan akun dengan level Kepsek saat melakukan proses login.

- Halaman Home

Pada halaman ini, terdapat link untuk mengakses halaman laporan data guru, laporan data siswa, laporan jadwal, laporan nilai, dan laporan absensi kelas. Berikut adalah tampilan halaman home kepala sekolah dapat dilihat pada gambar 20 .

Gambar 20. Tampilan Home Kepala Sekolah.

- Halaman Laporan Data Guru Pada halaman ini, Kepsek dapat mencetak laporan data guru, berdasarkan yang diinput oleh admin. Berikut adalah tampilan halaman laporan data guru dapat dilihat pada gambar 21 . 
Gambar 21. Tampilan Halaman Laporan Data Guru.

\section{- Halaman Laporan Data Siswa} Pada halaman ini, Kepsek dapat mencetak laporan data siswa, berdasarkan yang diinput oleh admin. Berikut adalah tampilan halaman laporan data siswa dapat dilihat pada gambar 22 .

Gambar 22. Tampilan Halaman Laporan Data Siswa.

- Halaman Laporan Jadwal Mata Pelajaran Pada halaman ini, Kepsek dapat mencetak laporan jadwal mata pelajaran, berdasarkan yang diinput oleh admin. Berikut adalah tampilan halaman laporan jadwal mata pelajaran dapat dilihat pada gambar 23 .
Gambar 23. Tampilan Halaman Laporan Jadwal.

\section{- Halaman Laporan Nilai}

Pada halaman ini, kepala sekolah dan admin dapat mencetak laporan nilai, berdasarkan yang diinput oleh admin. Berikut adalah tampilan halaman laporan nilai siswa dapat dilihat pada gambar 24 .

Gambar 24. Tampilan Halaman Laporan Nilai.

- Halaman Laporan Absensi Siswa Pada halaman ini, kepala sekolah dan admin dapat mencetak laporan absensi siswa, berdasarkan yang diinput oleh admin. Berikut adalah tampilan halaman laporan absensi siswa dapat dilihat pada gambar 25 . 


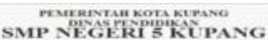
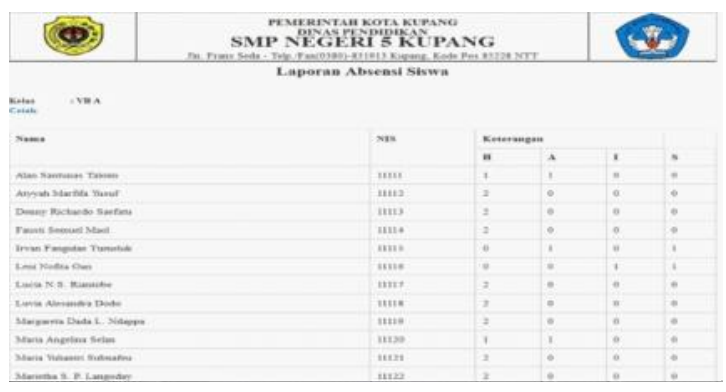

Gambar 25. Tampilan Halaman Laporan Absensi Siswa.

\section{PENUTUP}

\subsection{Kesimpulan}

Berdasarkan uraian yang telah dijelaskan pada bab sebelumnya, dapat disimpulkan bahwa:

a. Sistem yang dibuat menggunakan bahasa pemrograman PHP ini menghasilkan laporan berupa; laporan data guru, data siswa, jadwal mata pelajaran, nilai, dan absensi siswa.

b.Sistem tidak mengalami error setelah dilakukan percobaan, baik itu fungsi tombol yang ada pada setiap halaman, ataupun memproses data baik itu menambah, mengubah, atau menghapus data.

\subsection{Saran}

Adapun saran yang diusulkan untuk membuat sistem ini menjadi lebih baik adalah : a. Agar penyajian informasi menjadi lebih sempurna maka perlu ditambah raport siswa untuk penilaian terhadap hasil belajar, dan hasil ujian siswa, agar guru bisa memantau peringkat nilai dan memudahkan proses penilaian.

b.Mengimplementasikan sistem yang telah dibuat ke dalam internet, untuk mengetahui sistem dapat berjalan dengan baik atau tidak.

\section{DAFTAR PUSTAKA}

Jogiyanto, HM. 2002. Analisis dan Desain system Informasi. Yogyakarta: Andi.

Jogiyanto, HM. 2005. Analisis dan Desain Sistem Informasi : Pendekatan Terstruktur Teori dan Praktik Aplikasi Bisnis. Yogyakarta: Andi.

Junidar. 2012. Perancangan Sistem Informasi Akademik Di Universitas U'Budiyah Indonesia menggunakan PHP dan MySQL. Banda Aceh : STMIK U'Budiyah Indonesia.

Kristanto, Andri. 2008. Perancangan Sistem Informasi dan Aplikasinya. Yogyakarta: Gava Media.

Purwanto, 2014."Sistem Informasi Akademik SMP Neneri 27 Surakarta Berbasis Client server".Teknik Telekomunikasi ITS Surabaya.

Shannon, Weaver, 1992. "Ilmu Perpustakaan \& Informasi and A Mathematical.

Theory of Communication" http:/ spmc1.vub.ac.be/books/Shannon- Theory Comm.pdf

Turban, McLean, Wetherbe 1990. "Introduction to Information Tecnology" New York: John Wiley \& sons.

Dillak, R., \& toamnanu, n. (2017). SISTEM INFORMASI PENELITIAN RUTIN BERBASIS WEB DI UNIT PENELITIAN DAN PENGABDIAN MASYARAKAT RUTIN (UPPM) POLITEKNIK NEGERI KUPANG. Jurnal Ilmiah Flash, 3(1), 17-27. doi:10.5281/zenodo.1117129 